\title{
Adsorption and Desorption of Cd: Characteristics and Mechanisms in Reclaimed Soil Under the Influence of Dissolved Organic Carbon
}

\section{Yonghong Zheng}

Anhui University of Science and Technology

Zhiguo Zhang ( $\sim$ zzgaust@aust.edu.cn )

Anhui University of Science and Technology

Yongchun Chen

Huainan Mining(Group)Co.LTD

Shikai An

Huainan Minning(Group)Co.LTD

Lei Zhang

Anhui University of Science and Technology

\section{Fangling Chen}

Anhui University of Science and Technology

Chengnan Ma

Anhui University of Science and Technology

Weiqing Cai

Anhui University of Science and Technology

\section{Research}

Keywords: Dissolved organic carbon, reclaimed soil, humic acid, cadmium

Posted Date: June 11th, 2021

DOI: https://doi.org/10.21203/rs.3.rs-607235/v1

License: (1) (1) This work is licensed under a Creative Commons Attribution 4.0 International License. Read Full License 


\section{Abstract}

Organic acids are widespread in the environment, where they play an important role in the adsorption, desorption, and migration of $\mathrm{Cd}$ in soil. This study evaluated the characteristics and mechanisms of $\mathrm{Cd}$ adsorption and desorption in reclaimed soil from the Panyi Mine, in the Huainan mining area (China), under the influence of humic acid (HA). The addition of HA inhibited the adsorption of $\mathrm{Cd}$ but enhanced its desorption in reclaimed soil. With an increasing concentration of added HA, the adsorption capacity of $\mathrm{Cd}$ in the reclaimed soil gradually decreased, while the desorption capacity gradually increased. That is, the adsorption inhibition/desorption promotion effect was stronger under higher concentrations of organic acid. Cd adsorption and desorption dynamics could be described as a logarithmic function of organic acid concentration. Kinetic curves for $\mathrm{Cd}$ adsorption and desorption in reclaimed soil under the influence of organic acid showed that both adsorption and desorption involved two stages: a fast reaction stage, followed by a slow reaction stage. The factors influencing the capacity of Cd adsorption and desorption in soil were analyzed by gray correlation analysis, and their resulting rank order was as follows: $\mathrm{Cd}$ concentration $>\mathrm{HA}$ concentration $>\mathrm{pH}>$ temperature. Using linear regression analysis, a multi-factor coupling functional model of soil $\mathrm{Cd}$ adsorption and desorption under the influence of DOC was established, in the form of $Y=a+b X_{H A}+c X_{T}+d X_{P H}+e X_{C d}$.

\section{Introduction}

Coal mining has been carried out in the Huainan mining area for 100 years. The large-scale mining of coal resources has inevitably generated substantial amounts of solid waste and coal gangue, but it has also led to land subsidence whose area continues to expand. Since 2003, coal gangue filling and soil covering techniques ${ }^{[1]}$ have been applied in the Huainan mining area to backfill subsided terrain (with coal gangue) up to the original surface elevation, thereby allowing the subsided area to be reused. Yet such reclamation activities have affected the soil quality in the mining area to a certain extent, in that the soil is easily compacted, has a low nutrient content and large volume, and is potentially contaminated by heavy metals. In particular, the content of cadmium (Cd), a heavy metal, often exceeds the agricultural land filter value for soil pollution risk. ${ }^{[2-9]}$

Dissolved organic carbon (DOC) refers to organic carbohydrates with relatively low molecular weights and simple structures. Accordingly, DOC can be dissolved in water and passed through a $0.45-\mu \mathrm{m}$ microporous membrane, and it is the most active component of soil organic carbon ${ }^{[10-16]}$ and the main carrier of many trace organic and inorganic pollutants. DOC reacts directly with metal ions in water, soil, and sediment through a series of reactions, such as ion exchange, adsorption, complexation, chelation, flocculation, and precipitation, ${ }^{[17-19]}$ which modulates the adsorption and desorption behaviors of heavy metals in soil. Therefore, changes in the content of DOC are expected to lead to changed contents of heavy metals in soil. Research has shown that DOC in soil can affect the adsorption of heavy metals and improve their mobility in soil. ${ }^{[20]}$ For example, Mahara et al. ${ }^{[21]}$ reported that low-molecular-weight DOC in soil strongly affected the migration and transformation of $\mathrm{Cd}$ in the environment, and recently Zhang ${ }^{[22]}$ 
uncovered a strong correlation between dissolved heavy metals in the natural environment and the concentration of DOC. Liu ${ }^{[23]}$ had reported that DOC easily adsorbs and binds Cd in the soil: specifically, adding DOC to soil was able to increase the content of soil-exchanged Cd, resulting in a significant positive correlation between soil-exchanged Cd and soil DOC.

Research to date on soil DOC in China and elsewhere has mainly focused on the distribution and composition of DOC in soil, vegetation coverage, and soil fertilization, as well as the adsorption, desorption, complexation, dissociation, precipitation, and dissolution of soil heavy metal ions in the presence of DOC. However, the basic chemical equilibriums along with their corresponding mechanisms, laws, kinetic processes and multi-factor coupling models associated with the interactions between soil DOC and heavy metals have all received relatively less attention from scientists. In this study, reclaimed soil in the subsidence area of Panyi Mine was chosen as the research object. Humic acid (HA), which harbors the largest content of soluble humus, was selected as a representative DOC molecule. The HA was used to prepare DOC solutions at different concentrations, which were then applied to determine the effects of DOC upon the characteristics and kinetics of Cd adsorption and desorption in soil, for which a multi-factor coupling model was sought and developed. The results provide not only fundamental data for evaluating the $\mathrm{Cd}$ pollution status of reclaimed soil of coal mines but also a robust scientific method for risk assessment and prediction. This study's findings could also offer guidance for the rational application of organic materials.

\section{Materials And Methods \\ 2.1 Study area}

The Panyi Mine Reclamation Area is located approximately $1.0 \mathrm{~km}$ east of the Panyi Mine, in the Panji District, Huainan City (China). A coal gangue hill is located on the southern side of the reclamation area. This reclamation area was formed by the filling and rolling of coal gangue into the coal mining subsidence area, the coal gangue is covered by clay with a design thickness of $100 \mathrm{~cm}$. After that treatment, several tree species including poplar, privet, metasequoia, cedar, and Sichuan juniper were planted in the subsidence area. This area lies in a warm temperate semi-humid continental monsoon climate zone. The average annual temperature is $15.3^{\circ} \mathrm{C}$, with the highest and lowest temperatures respectively occurring in July and January, while the average annual precipitation is $926 \mathrm{~mm}$.

\subsection{Sample collection and pretreatment}

Three sampling lines were established in the Panyi Mine Reclamation Area. Along each line, a sampling point was established every $5 \mathrm{~m}$, for a total of 60 sampling points. At each sampling point, a soil heavy metal sampler was used to collect $0-20 \mathrm{~cm}$ of reclaimed soil. Each sample had a mass of at least $1 \mathrm{~kg}$. After removing any impurities, the soil sample was crushed and spread flat on an air-dried soil dish to dry. 
Each sample was sieved using the quarter method, ground with an agate mortar, passed through a 100mesh nylon screen, packed in a Ziploc bag, and then labeled for use.

\subsection{Experimental method}

As mentioned above, HA was selected as the representative DOC molecule. HA was used to prepare DOC solutions with different concentrations.

2.3.1 Adsorption of Cd in reclaimed soil under the influence of DOC

A given sample of reclaimed soil (1.000 g, passed through an 18-mesh screen) was weighed and placed in a $50-\mathrm{mL}$ centrifuge tube. Then, $20 \mathrm{~mL}$ of a $\mathrm{Cd}\left(\mathrm{NO}_{3}\right)_{2}$ solution having a $\mathrm{Cd}$ concentration of $0,0.2,0.4$, $0.6,0.8,1,1.5,2,2.5,3,4,5,8,10,15,20,25,30,35,40,45,50,55,60,65,70,75$, or $80 \mathrm{mg} / \mathrm{L}$ was added to the centrifuge tube, followed by the addition of $1 \mathrm{~mL}$ of $\mathrm{HA}$ solution whose concentration was 10 $\mathrm{mg} / \mathrm{L}$. The centrifuge tube was immediately capped, shaken at $200 \mathrm{r} / \mathrm{min}$ at a constant temperature of $25^{\circ} \mathrm{C}$ for $24 \mathrm{~h}$, and then centrifuged at $4000 \mathrm{r} / \mathrm{min}$ for $20 \mathrm{~min}$. Finally, the supernatant was passed through a $0.45-\mu \mathrm{m}$ filter membrane, and one drop of $1 \%$ nitric acid was added to the filtrate followed by shaking for the $C d$ determination. The $C d$ adsorption capacity $\left(Q_{a}\right.$, in $\left.\mathrm{mg} / \mathrm{kg}\right)$ was determined as the difference between the concentration of $\mathrm{Cd}$ before and after its adsorption:

$$
Q_{a}=\frac{c_{0}-C \times V}{m}
$$

where $C_{0}$ is the concentration of $C d$ in the initial solution $(\mathrm{mg} / \mathrm{L}), C$ is the concentration of $C d$ in the equilibrium solution at an adsorption equilibrium $(\mathrm{mg} / \mathrm{L}), V$ is the initial volume of liquid added $(\mathrm{mL})$, and $m$ is the mass of the sample $(\mathrm{g})$. A control experiment was simultaneously carried out with an HA solution $(60 \mathrm{mg} / \mathrm{L})$.

\subsubsection{Desorption of Cd from reclaimed soil under the influence of DOC}

The desorption experiment was performed upon completing the adsorption experiment. The reclaimed soil after $\mathrm{Cd}$ adsorption was washed once with absolute ethanol to remove any free $\mathrm{Cd}$ and placed at a constant temperature $\left(25^{\circ} \mathrm{C}\right)$ for $1 \mathrm{~h}$. Next, $20 \mathrm{~mL}$ of $\mathrm{NaNO}_{3}$ solution $(0.01 \mathrm{~mol} / \mathrm{L})$ was added to the soil, followed by its covering and shaking at $200 \mathrm{r} / \mathrm{min}$ and $25^{\circ} \mathrm{C}$ for $24 \mathrm{~h}$. The solution was then centrifuged at $4000 \mathrm{r} / \mathrm{min}$ for $20 \mathrm{~min}$. Finally, the supernatant was filtered through a $0.45-\mu \mathrm{m}$ membrane, and one drop of $1 \%$ nitric acid was added to the filtrate followed by shaking for the $\mathrm{Cd}$ determination. The $\mathrm{Cd}$ desorption capacity $\left(Q_{d}\right)$ was determined this way:

$$
Q_{d}=\frac{c \times V}{m}
$$

The Cd desorption rate $(W)$ was calculated as 
$W(\%)=\frac{Q_{d}}{Q_{a}} \times 100 \%$.

\subsubsection{Effects of $\mathrm{pH}$ on $\mathrm{Cd}$ adsorption and desorption in soil}

For this, the HA and Cd solutions were respectively set to a fixed concentration of $60 \mathrm{mg} / \mathrm{L}$ and $20 \mathrm{mg} / \mathrm{L}$, while the $\mathrm{pH}$ of soil samples was adjusted to $4.5,5,5.5,6,6.5,7,7.5,8,8.5,9,9.5,10$, or 10.5 at $25^{\circ} \mathrm{C}$. The specific steps consisted of putting a 1.000-g soil sample (passed through an 18 mesh screen) into a 50 $\mathrm{ml}$ centrifuge tube, to which was added $20 \mathrm{ml}$ of $\mathrm{Cd}\left(\mathrm{NO}_{3}\right)_{2}$ solution $(20 \mathrm{mg} / \mathrm{L}$ concentration of $\mathrm{Cd})$ followed by the addition of $1 \mathrm{ml}$ of the HA solution ( $60 \mathrm{mg} / \mathrm{L} \mathrm{Cd}$ concentration). The $\mathrm{pH}$ value of the sample was adjusted accordingly along the gradient ( $\mathrm{pH} 4.5$ to 10.5), with each sample removed at $25^{\circ} \mathrm{C}$ for $24 \mathrm{~h}$, and then centrifuged $(4000 \mathrm{r} / \mathrm{min})$ for $20 \mathrm{~min}$. The ensuing supernatant in the centrifuge tube was filtered through a $0.45-\mu \mathrm{m}$ membrane. After this filtration, one drop of $1 \%$ nitric acid was added to the filtered solution and shaken, the concentration of $\mathrm{Cd}$ was then determined. According to the difference in the $\mathrm{Cd}$ concentration before and after adsorption, the adsorption capacity was calculated using formula (1).

After completing the adsorption experiment, the corresponding desorption experiment was likewise carried out. To do this, soil samples that had adsorbed a certain amount of $\mathrm{Cd}$ were washed with anhydrous ethanol (washed once) and maintained at constant temperature $\left(25^{\circ} \mathrm{C}\right)$ for $1 \mathrm{~h}$. Next, $20 \mathrm{ml}$ of $0.01 \mathrm{~mol} / \mathrm{L} \mathrm{NaNO} 3$ solution was added and the $\mathrm{pH}$ value of a sample adjusted accordingly (pH gradient of 4.5 to 10.5 , as used above), then each tube was shaken at $25^{\circ} \mathrm{C}$ for $24 \mathrm{~h}$ and centrifuged for $20 \mathrm{~min}$. The supernatant in the samples' centrifuge tube was filtered by a $0.45-\mu \mathrm{m}$ membrane, and this filtrate was then shaken after adding to it one drop of $1 \%$ nitric acid. The concentration of $\mathrm{Cd}$ was determined. The desorption amount of $\mathrm{Cd}$ was calculated using formula (2).

\subsubsection{Effect of temperature on Cd adsorption and desorption in soil}

To each soil sample, the $60 \mathrm{mg} / \mathrm{L}$ HA solution and $20 \mathrm{mg} / \mathrm{L} \mathrm{Cd}$ solution were added. Under the condition of $\mathrm{pH} 7.5$, the temperature of the samples was adjusted to $5^{\circ} \mathrm{C}, 10^{\circ} \mathrm{C}, 15^{\circ} \mathrm{C}, 20^{\circ} \mathrm{C}, 25^{\circ} \mathrm{C}, 30^{\circ} \mathrm{C}, 35^{\circ} \mathrm{C}$, or $40^{\circ} \mathrm{C}$.

Specifically, a 1.000-g soil sample (first passed through an 18 mesh screen) was put into a $50-\mathrm{ml}$ centrifuge tube, to this was added $20 \mathrm{ml}$ of $\mathrm{Cd}\left(\mathrm{NO}_{3}\right)_{2}$ solution $(20 \mathrm{mg} / \mathrm{L} \mathrm{Cd})$, and then $1 \mathrm{ml}$ of the HA solution $(60 \mathrm{mg} / \mathrm{L} \mathrm{Cd})$ was added to each centrifuge tube. The samples were removed at the eight different temperatures $\left(5^{\circ} \mathrm{C}\right.$ to $40^{\circ} \mathrm{C}$ gradient) under constant temperature oscillation $(200 \mathrm{r} / \mathrm{min})$ for $24 \mathrm{~h}$ and centrifuged $(4000 \mathrm{r} / \mathrm{min})$ for $20 \mathrm{~min}$. The supernatant in the centrifuge tube was passed through a $0.45-\mu \mathrm{m}$ membrane. After this filtration, one drop of $1 \%$ nitric acid was added to the filtered solution and shaken, after which the concentration of $\mathrm{Cd}$ was determined. According to the difference in the $\mathrm{Cd}$ concentration before and after adsorption, the adsorption capacity was calculated using formula (1). 
The corresponding desorption experiment was carried out after the completion of the just-described adsorption experiment. The soil that had adsorbed a certain amount of $\mathrm{Cd}$ was washed with anhydrous ethanol to remove the free $\mathrm{Cd}$ (washed once). The soil was placed at $5^{\circ} \mathrm{C}, 10^{\circ} \mathrm{C}, 15^{\circ} \mathrm{C}, 20^{\circ} \mathrm{C}, 25^{\circ} \mathrm{C}, 30^{\circ} \mathrm{C}$, $35^{\circ} \mathrm{C}$, or $40^{\circ} \mathrm{C}$ for $1 \mathrm{~h}$. Then $20 \mathrm{ml}$ of $0.01 \mathrm{~mol} / \mathrm{L} \mathrm{NaNO}$ solution was added to each sample, and these removed in a constant temperature oscillator $(200 \mathrm{r} / \mathrm{min})$ for $24 \mathrm{~h}$ and centrifuged $(4000 \mathrm{r} / \mathrm{min})$ for 20 min. The supernatant in the centrifuge tube was filtered through a $0.45-\mu \mathrm{m}$ membrane, and the filtrate was shaken after adding to it one drop of $1 \%$ nitric acid. The concentration of $\mathrm{Cd}$ was determined. The desorption amount of $\mathrm{Cd}$ was calculated using formula (2).

\subsection{Data processing}

SPSS 24.0 software was used for the statistical analysis of the data, Origin8.0 software was used for drawing the figures, and MATLAB mathematical software was used to compile the corresponding calculation program for the gray correlation ${ }^{[40]}$ analysis. According to the statistics for $\mathrm{Cd}$ adsorption capacity, desorption capacity, and various factors, 74 samples were analyzed, for which the order number was $\mathrm{m}=4$ (HA concentration, $\mathrm{Cd}$ concentration, temperature, and $\mathrm{pH}$ value) $\mathrm{P}=0.5$. Using the MATLAB calculations, the gray correlation degree of $\mathrm{HA}$ concentration, $\mathrm{Cd}$ concentration, temperature, and $\mathrm{pH}$ value are listed in Table 1. To establish the best adsorption and desorption model as function of HA concentration, Cd concentration, $\mathrm{pH}$ value, and temperature (at a 95\% confidence interval), these four predictors were entered into a multiple linear regression (but with no interaction terms). In this model, the response variable $\mathrm{Y}$ is the adsorption capacity of $\mathrm{Cd}$ in the solution, $\mathrm{X}_{\mathrm{HA}}$ is the concentration of $\mathrm{HA}, \mathrm{X}_{\mathrm{Cd}}$ is the concentration of $\mathrm{Cd}$ in the solution, $\mathrm{X}_{\mathrm{T}}$ is the solution temperature, and $\mathrm{X}_{\mathrm{PH}}$ is the $\mathrm{pH}$ of the solution.

\section{Results And Discussion}

\subsection{Characteristics and mechanism of isothermal $\mathrm{Cd}$ adsorption under the influence of HA}

As Fig. 1 shows, as the concentration of $\mathrm{Cd}$ in the equilibrium solution increased, the adsorption capacity of reclaimed soil for $\mathrm{Cd}$ gradually increased. When the $\mathrm{Cd}$ concentration was low (i.e., $0.2-10 \mathrm{mg} / \mathrm{L}$ ), the amount of adsorbed $\mathrm{Cd}$ was similar in the presence and absence of HA. Thus, under low $\mathrm{Cd}$ concentrations, HA has little effect on the ability of reclaimed soil to adsorb Cd. By contrast, when the Cd concentration was 15-80 mg/L, the presence of HA significantly reduced the adsorption of $\mathrm{Cd}$ by the reclaimed soil, and the amount of adsorbed Cd decreased as the concentration of added Cd increased. Thus, adding HA significantly inhibits the adsorption of $\mathrm{Cd}$ by reclaimed soil. Notably, the high organic acid concentration $(60 \mathrm{mg} / \mathrm{L})$ produced a stronger effect than did adding the low concentration (10 $\mathrm{mg} / \mathrm{L}$ ). Studies have shown that different DOC components can affect the migration of organic and inorganic pollutants in soil. ${ }^{[12,24-27]}$ We know that HA contains a variety of active groups. In particular, HA harbors abundant benzene rings, carboxyl groups, alcoholic hydroxyl groups, phenolic hydroxyl groups, 
and amino groups, all of which can undergo exchange, adsorption, and chelation reactions with various heavy metals. ${ }^{[28-31]}$ These sites compete with the reclaimed soil to adsorb $\mathrm{Cd}$, thereby reducing the ability of the soil to readily adsorb $\mathrm{Cd}$. The ionization of $\mathrm{H}^{+}$in the oxygen-containing functional groups of $\mathrm{HA}$ reduces the $\mathrm{pH}$ of the reclaimed soil solution, thereby changing the metal solubility and further reducing the Cd adsorption capacity of the soil. ${ }^{[32-35]}$ Furthermore, HA, which is rich in anionic groups, such as phenolic, hydroxyl, and carboxyl groups, precedes $\mathrm{Cd}$ at occupying the soil seat sites via soil surface adsorption, ${ }^{[36-37]}$ thereby reducing the $\mathrm{Cd}$ adsorption capacity of reclaimed soil. This interpretation of results is consistent with other findings indicating that DOC has a significant inhibitory effect on $\mathrm{Cd}$ adsorption in soil. ${ }^{[38]}$

\subsection{Characteristics and mechanism of isothermal $\mathrm{Cd}$ desorption under the influence of HA}

As seen in Fig. 2, with an increased concentration of $\mathrm{Cd}$ in the equilibrium solution, the Cd desorption capacity of reclaimed soil gradually increased as well. When the $\mathrm{Cd}$ concentration was low $(0.2-10$ $\mathrm{mg} / \mathrm{L}$ ), the amounts of desorbed $\mathrm{Cd}$ were similar irrespective of HA. Thus, under low $\mathrm{Cd}$ concentrations, HA negligibly affects the ability of reclaimed soil to desorb $\mathrm{Cd}$. However, when the Cd concentration was $15-80 \mathrm{mg} / \mathrm{L}$, the presence of HA significantly increased the desorption of $\mathrm{Cd}$ in the reclaimed soil, and the amount of desorbed $\mathrm{Cd}$ increased as the concentration of added Cd increased. Due to the differing physical and chemical properties of reclaimed soils, HA had different effects on desorption capacity. Using a high organic acid concentration $(60 \mathrm{mg} / \mathrm{L})$ produced a larger effect than did a low concentration (10 mg/L).

The desorption rate of $\mathrm{Cd}$ from reclaimed soil increased upon the addition of HA (Fig. 3). The Cd desorption rate of reclaimed soil increased, on average, by $5.71 \%$ and $3.21 \%$ upon the addition of high (60 $\mathrm{mg} / \mathrm{L})$ and low $(10 \mathrm{mg} / \mathrm{L})$ concentrations of $\mathrm{HA}$, respectively. The adsorption process of $\mathrm{Cd}$ is one dominated by chemical bonding and electrostatic attraction; the activation energy required for adsorption is low, while the adsorption affinity is high. Unlike that, the desorption process of $\mathrm{Cd}$ is an ion exchange process. Organic ligands contained in organic acids can form soluble organometallic complexes with $\mathrm{Cd}$, thereby reducing the adsorption of $\mathrm{Cd}$ in reclaimed soil. Moreover, the protons in HA can activate $\mathrm{Cd}$ in reclaimed soil and this also promotes its desorption. ${ }^{[39]}$

\subsection{Kinetics and mechanism of Cd adsorption and desorption under the influence of HA}

As depicted in Fig. 4, when compared with the normal (untreated) reclaimed soil, Cd adsorption was significantly reduced in the soil containing HA. Under the influence of HA, Cd adsorption was reduced by $17.06-18.80 \%$ (average: $18.18 \%$ ). These results demonstrate that $\mathrm{HA}$ is capable of changing the migration behavior of $\mathrm{Cd}$ in the reclaimed soil by affecting its adsorption.

The adsorption process of $\mathrm{Cd}$ in the reclaimed soil containing HA was the same as in that lacking it. Adsorption began with a fast adsorption stage, lasting just $0-0.5 \mathrm{~h}$, followed by a slow adsorption stage 
lasting 1-12 h. In the fast absorption stage, the adsorption capacity of $\mathrm{Cd}$ in reclaimed soil increased rapidly. Under the influence of $\mathrm{HA}$, the $\mathrm{Cd}$ adsorption rate was $71.36 \%$, corresponding to a reduction of $15.04 \%$ relative to the normal reclaimed soil. These results further demonstrate that HA can inhibit the adsorption of $\mathrm{Cd}$ in reclaimed soil.

Under the influence of $\mathrm{HA}$, the $\mathrm{Cd}$ desorption capacity in reclaimed soil first decreased and then increased over time, revealing two desorption stages (Fig. 5): a fast reaction stage spanning 0 to $2 \mathrm{~h}$ at the beginning of the experiment, followed by a slow reaction stage spanning 2.5 to $12 \mathrm{~h}$. Within the first $2 \mathrm{~h}$, the desorption capacity diminished rapidly, reaching its lowest value at $2 \mathrm{~h}$. In the subsequent slow reaction stage, the desorption capacity increased slowly, attaining equilibrium after approximately $12 \mathrm{~h}$. Including $\mathrm{HA}$ significantly increased the desorption capacity of $\mathrm{Cd}$ in reclaimed soil; $\mathrm{HA}$ increased the $\mathrm{Cd}$ desorption capacity by $28.51-72.98 \%$ (average: $50.29 \%$ ). These results demonstrate that HA can alter the migration activity of $\mathrm{Cd}$ in reclaimed soil by affecting the desorption of $\mathrm{Cd}$.

\subsection{Multi-factor coupling model of Cd adsorption and desorption in soil}

\subsubsection{Correlation analysis}

According to Table 1, the rank order of influencing factors of $\mathrm{Cd}$ adsorption and desorption is $\mathrm{Cd}$ concentration $>\mathrm{HA}$ concentration $>\mathrm{pH}>$ temperature. These results indicate that among the considered factors that could influence the adsorption and desorption of $\mathrm{Cd}$, its concentration was the decisive factor, followed by the HA concentration, $\mathrm{pH}$ value, and temperature.

Table 1

Correlations of influencing factors of coal gangue weathering matter and soil.

\begin{tabular}{|lllll|}
\hline \multicolumn{5}{|c|}{ Correlation degree } \\
\hline & HA & $\mathrm{Cd}$ & Temperature & $\mathrm{pH}$ \\
\hline Soil adsorption & 0.7199 & 0.8762 & 0.6369 & 0.7033 \\
Soil desorption & 0.7666 & 0.9184 & 0.6922 & 0.7562 \\
\hline
\end{tabular}

\subsubsection{Multiple regression analysis}

Two linear models were built to explain the adsorption and desorption of $\mathrm{Cd}$ based on the $\mathrm{Cd}$ concentration, $\mathrm{HA}$ concentration, $\mathrm{pH}$, and temperature coupling showed an excellent fit to the data. Furthermore, the relative error ( $\mathrm{dX}[\%])$ between the predicted and measured values were analyzed by applying the established linear coupling-function model. Doing so shows that it can reliably predict the changes in soil Cd adsorption and desorption under the influence of multiple factors (Table 3). 
Table 2 Multi-factor coupling model for the adsorption and desorption of $\mathrm{Cd}$ in coal gangue weathering matter and soil.

\begin{tabular}{|llllll|}
\hline Sample & Type & Multiple linear regression model & $\mathrm{R}^{2}$ & $\mathrm{~F}$ & $\mathrm{P}$ \\
\hline Soil & $\begin{array}{l}\text { Adsorption } \\
\text { model }\end{array}$ & $\begin{array}{l}\mathrm{Y}=-32.176- \\
2.024 \mathrm{X}_{\mathrm{HA}}+1.325 \mathrm{X}_{\mathrm{T}}+18.352 \mathrm{X}_{\mathrm{pH}}+14.974 \mathrm{X}_{\mathrm{Cd}}\end{array}$ & 0.991 & 914.00 & 0 \\
& $\begin{array}{l}\text { Desorption } \\
\text { model }\end{array}$ & $\begin{array}{l}\mathrm{Y}=36.368+0.047 \mathrm{X}_{\mathrm{HA}}-0.590 \mathrm{X}_{\mathrm{T}}- \\
3.556 \mathrm{X}_{\mathrm{pH}}+2.373 \mathrm{X}_{\mathrm{Cd}}\end{array}$ & 0.987 & 672.90 & 0 \\
& & & & \\
\hline
\end{tabular}

Table 3 Comparison of observed and predicted values of the multiple linear regression model.

\begin{tabular}{|ll|}
\hline Type & Relative error dx (\%) \\
\hline Cd adsorption capacity of soil & $-2.97 \sim 1.74$ \\
\hline Cd desorption capacity of soil & $-3.01 \sim 3.20$ \\
\hline
\end{tabular}

Therefore, the adsorption and desorption of $\mathrm{Cd}$ in soil is determined by the $\mathrm{Cd}$ concentration, HA concentration, $\mathrm{pH}$ value, and temperature. The above model can be used to predict and verify the characteristics of $\mathrm{Cd}$ adsorption and desorption in the Huainan reclamation area (and perhaps other similar to it).

\subsubsection{Three-dimensional (3D) diagrams of the multi-factor coupling function model}

In this paper, MATLAB software was used to draw the 3D graphs of each multi-factor coupling model, because this can more clearly and intuitively describe the relationships between the adsorption or desorption capacity for $\mathrm{Cd}$ and various factors influencing in soil. According to the multi-factor coupling model $\mathrm{Y}=-32.176-2.024 \mathrm{X}_{\mathrm{HA}}+1.325 \mathrm{X}_{\mathrm{T}}+18.352 \mathrm{X}_{\mathrm{PH}}+14.974 \mathrm{X}_{\mathrm{Cd}}$, the $3 \mathrm{D}$ diagrams were drawn, as shown in Figs. 6-9.

Figure 6 shows that when the HA concentration is $60 \mathrm{mg} / \mathrm{L}$, the adsorption capacity of $\mathrm{Cd}$ is strengthened by an increasing $\mathrm{Cd}$ concentration; with a greater $\mathrm{pH}$ value, the adsorption capacity of $\mathrm{Cd}$ is also enhanced; further, with a higher temperature, the adsorption capacity of $\mathrm{Cd}$ is enhanced as well. Figure 7 shows that when the temperature is $25^{\circ} \mathrm{C}$, with an increasing $\mathrm{HA}$ concentration, the adsorption capacity of $\mathrm{Cd}$ decreases; however, with an increased $\mathrm{Cd}$ concentration, the adsorption capacity of $\mathrm{Cd}$ is augmented; similarly, with an increased $\mathrm{pH}$ value, the adsorption capacity of $\mathrm{Cd}$ is also augmented. Figure 8 shows that when the $\mathrm{pH}$ value is 7.5 , increasing the $\mathrm{HA}$ concentration decreases the adsorption capacity of $\mathrm{Cd}$ in soil; conversely, with an increased $\mathrm{Cd}$ concentration or temperature, the adsorption capacity of $\mathrm{Cd}$ is also increased. Figure 9 shows that when the $\mathrm{Cd}$ concentration is $20 \mathrm{mg} / \mathrm{L}$, the adsorption capacity of $\mathrm{Cd}$ decreases with as the HA concentration increases; but with a greater $\mathrm{pH}$ value or higher temperature, the adsorption capacity of Cd increases. 
According to the multi-factor coupling model $\mathrm{Y}=36.368+0.047 \mathrm{X}_{\mathrm{HA}}-0.590 \mathrm{X}_{\mathrm{T}}-3.556 \mathrm{X}_{\mathrm{PH}}+2.373 \mathrm{X}_{\mathrm{Cd}}$, the 3D diagrams were drawn, as shown in Figs. 10-13.

Figure 10 shows that when HA concentration is $60 \mathrm{mg} / \mathrm{L}$, the desorption of Cd increases with an increasing $\mathrm{Cd}$ concentration; but with a rising $\mathrm{pH}$ or temperature, the desorption of $\mathrm{Cd}$ decreases. Figure 11 shows that when the temperature is $25^{\circ} \mathrm{C}$, the desorption of $\mathrm{Cd}$ is enhanced by increasing concentrations of $\mathrm{HA}$ or $\mathrm{Cd}$, whereas with a greater $\mathrm{pH}$ value, the desorption of $\mathrm{Cd}$ is diminished. Figure 12 shows that when the $\mathrm{pH}$ value is 7.5 , the desorption of $\mathrm{Cd}$ increases with an increasing $\mathrm{HA}$ concentration; likewise, with an increase in the Cd concentration, the desorption of $\mathrm{Cd}$ also increases; however, with a rising temperature, the desorption of $\mathrm{Cd}$ decreases. Finally, Fig. 13 shows that when the concentration of $\mathrm{Cd}$ is $20 \mathrm{mg} / \mathrm{L}$, the desorption of $\mathrm{Cd}$ increases with an increasing HA concentration, whereas with either an increase in the $\mathrm{pH}$ value or temperature, the desorption of $\mathrm{Cd}$ decreases.

\section{Conclusions}

The effects of organic acids on Cd adsorption and desorption dynamics in reclaimed soil are complicated. In this study, the addition of humic acid (HA) inhibited the adsorption of $\mathrm{Cd}$ in the reclaimed soil of a coal mine. Further, HA strengthened the process of $\mathrm{Cd}$ desorption in the same reclaimed soil. The adsorption and desorption kinetics of $\mathrm{Cd}$ in reclaimed soil were significantly affected by time, which could be divided into two stages: an initial fast reaction stage that was followed by a slow reaction stage. The factors influencing the $\mathrm{Cd}$ adsorption and desorption capacity in soil were investigated by gray correlation analysis, which revealed their rank order: $\mathrm{Cd}$ concentration > HA concentration > $\mathrm{pH}>$ temperature. By using regression methods, a multi-factor coupling function model of soil Cd adsorption and desorption under the influence of DOC was established: $\mathrm{Y}=\mathrm{a}+\mathrm{bX} \mathrm{XA}_{\mathrm{HA}}+\mathrm{cX} \mathrm{X}_{\mathrm{T}}+\mathrm{dX}_{\mathrm{PH}}+\mathrm{eX}_{\mathrm{Cd}}$. Hence, this model may be used to predict and verify the characteristics of $\mathrm{Cd}$ adsorption and desorption. It could also be applied to improve the $\mathrm{Cd}$ migration ability in soil by manipulating the levels of four influencing factors in combination with phytoremediation technology to achieve the goal of removing Cd pollution from soil entirely.

\section{Declarations}

\section{Acknowledgments:}

This research was supported by the Natural Science Research Project of University in Anhui Province (No. KJ2018A0072), the National Natural Science Foundation of China (No. 51904014), and the Postdoctoral Foundation of Anhui Province (No. 2019B337). The authors appreciate the constructive comments from an anonymous reviewer.

\section{References}


1. Bian Z (2001) Research on the succession law and regulation of interface elements of land reclamation in mining area. Higher Education Press, Beijing.

2. Yao D, Meng J, Zhang Z et al (2010) Heavy metal pollution and potential ecological risk in reclaimed soils in Huainan mining area. Journal of Coal Science and Engineering (China) 16:316-319.

3. Zhang Z, Yao D, Zheng Y et al (2010) Research on soil heavy metal pollution remediation potential of six compositae plants in coal mine subsidence reclamation area. Journal of China Coal Society 35:1742-1747.

4. Zhao Y, Zhang T, Tian Z et al (2020) Research progress in phytoremediation technology of heavy metal contaminated soil around mining area. Urban Geology 15:22-33.

5. He L (2019) Research on chemical remediation technology of heavy metal contaminated soil in mining area. Henan Science and Technology 11:134-136.

6. Jiang B, Zhang B, Wang $X$ et al (2020) Soil heavy metal pollution and potential risk assessment in Fushun West Open-pit Mine. Journal of Northeastern University (Natural Science Edition) 41:568-574.

7. Zhang B, Mi W, Xiao Y et al (2019) The current status of soil heavy metal pollution in coal mining areas and an overview of its evaluation method. Proceedings of the Chinese Society of Environmental Sciences 2019 Annual Conference 2946-2951.

8. Li H, Yan S, Cui L et al (2008) Evaluation of soil heavy metal pollution in Huainan Xinji mining area. Mining Safety and Environmental Protection 35:36-37.

9. Xie C, Qin Y, Chao L et al (2020) Applied research on the numerical simulation of Cu and Cd transport laws in a metal mining area. AIP Advances 10:2158-3226.

10. Kalbitz K, Solinger S Park JH et al (2000) Controls on the dynamics of dissolved organic matter in soils: a review. Soil Science 165:277-304.

11. Yang L, Zhang J, Yang GP et al (2020) Mixing behavior, biological and photolytic degradation of dissolved organic matter in the East China Sea and the Yellow Sea. Science of the Total Environment 762:143164.

12. Li S, Yu Y, He S et al (2003) The relationship between dissolved organic carbon and soil factors in southern forest soils. Journal of Zhejiang Forestry College 20:119-123.

13. Ye J (2020) The composition and structure characteristics of soil dissolved organic matter and its effect on cadmium phytotoxicity. Dissertation, Wuhan University of Science and Technology.

14. Wang C, Xue L, Dong Y et al (2020) Soil organic carbon fractions, C-cycling hydrolytic enzymes, and microbial carbon metabolism in Chinese fir plantations. Science of the Total Environment 758:143695.

15. Liu C (2019) Sources and impact mechanisms of eroded soil organic carbon in the hilly area of the Loess Plateau. Dissertation, Hunan University.

16. Huang Q, Wu J, Chen J, et al (2015) Research progress in soil adsorption of soluble organic carbon. Soil 47:446-452. 
17. Yang J, Zeng $X$ (2007) Chemical behavior of water-soluble organic matter in soil and its impact on the environment. Chinese Journal of Eco-Agriculture 615:206-211.

18. Wang Q (2016) Research on the influence of freeze-thaw and snow-melt processes on dissolved organic matter in soil. Dissertation, Liaoning University.

19. Li W (2017) The structure composition and environmental effects of dissolved humus in Lake Taihu. Dissertation, East China Normal University.

20. Jagadamma S, Mayes MA, Zinn YL et al (2014) Sorption of organic carbon compounds to the fine fraction of surface and subsurface soils. Geoderma 213:79-86.

21. Mahara Y, Kubota T, Wakayama R et al (2007) Effects of molecular weight of natural organic matter on cadmium mobility in soil environments and its carbon isotope characteristics. Science of the Total Environment 387:220-227.

22. Zhang S (2020) The characteristics of dissolved organic matter in the black and smelly river and its correlation with heavy metals. Dissertation, Northwest Normal University.

23. Liu G (2019) The effect of organic materials on the dissolved organic matter of purple soil and the accumulation of cadmium in rice. Dissertation, Southwest University.

24. Zsolnay A (1996) Dissolved humus in soil waters. In: Piccolo A, ed. Humic Substances in Terrestrial Ecosystems. Elsevier, Amsterdam, pp. 171-223.

25. Gao T, Zhang H, Zhou J et al (2011) The influence of dissolved organic matter on the environmental behavior of heavy metals in soil. Journal of Ecological Environment 20:652-658.

26. Lei H, Pan H, Han Y et al (2015) Spectroscopic study on the influence of dissolved organic matter on pesticide residues and distribution in soil. Spectroscopy and Spectral Analysis 35:1926-1932.

27. Bhattacharya R, Osburn CL (2020) Chromophoric dissolved organic matter composition and load from a coastal river system under variable flow regimes. Science of the Total Environment 760:143414.

28. Ma Y, Xie G, Liu Z et al (2020) On the repair principle of humic acid and food safety. Food Safety Guide 16:55-57.

29. Shan R, Huang Z, Ke C et al (2015) The leaching effect of humic acid on soil heavy metal cadmium and the mechanism of adsorption and desorption. Humic Acid 1:12-17.

30. Xu Y, Wu P, Dang Z et al (2008) Experimental study on the adsorption of heavy metal ions by montmorillonite/humic acid complex. Impurities in Rock and Mineralogy 27:221-226.

31. Huang $J(2020)$ The effect of exogenous organic acids on the migration of $\mathrm{Cd}$ in the soil-rice system. Dissertation, Central South University of Forestry and Technology.

32. Li J, Zhang J, Li Y et al (2018) Analysis of the influence of dissolved organic matter on soil heavy metal activity. Southern Agriculture 12:62-64.

33. Yang $Y(2018)$ Study on the effects of two organic acids on the adsorption-desorption characteristics of $\mathrm{Zn \sim (2+)}$ and $\mathrm{Cd} \sim(2+)$ in tea garden soil aggregates. Dissertation, Sichuan Agricultural University. 
34. Yan A (2019) Study on the adsorption characteristics and mechanism of soil humic substances on heavy metals. Dissertation, Jilin Agricultural University.

35. Jagadamma S, Maye MA, Zinn YL et al (2014) Sorption of organic carbon compounds to the fine fraction of surface and subsurface soils. Geoderma 213:79-86.

36. He J, Lu W, Zhang N et al (2020) Research progress in the application of humic acid in the remediation of heavy metal contaminated soil. Humic Acid 02:38-42+55.

37. Izosimova Y, Tolpeshta I, Gurova I et al (2020) Sorption of Cu2+ ions by bentonite Modified with Al keggin cations and humic acid in solutions with pH 4.5. Minerals 12:1121.

38. Chen TB, Chen ZJ (2002) Cadmium adsorption in soil as influenced by dissolved organic matter derived from rice straw sediment. Chinese Journal of Applied Ecology 2:156-159.

39. Xu R, Li X, Sun L et al (2015) The leaching kinetic characteristics and removal mechanism of Pb and Cd in soil by organic acids. Journal of Safety and Environment 15:261-266.

40. Deng J (2005) The Primary Methods of Grey System Theory. WuHan: Huazhong University Of Science And Technology Press.

\section{Figures}

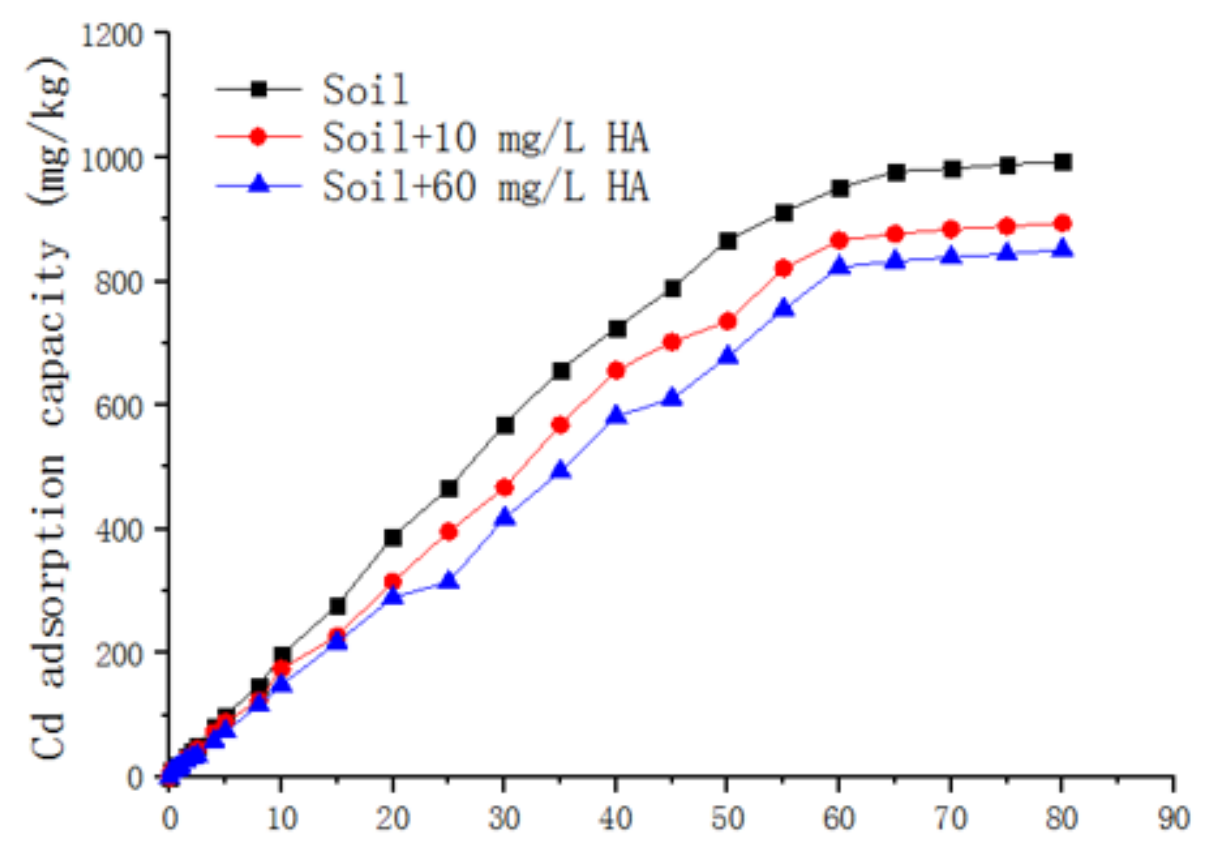

$\mathrm{Cd}$ concentration in equilibrium solution (mg/L)

\section{Figure 1}

Cd adsorption capacity versus the Cd concentration in solution in the presence and absence of $\mathrm{HA}$. 


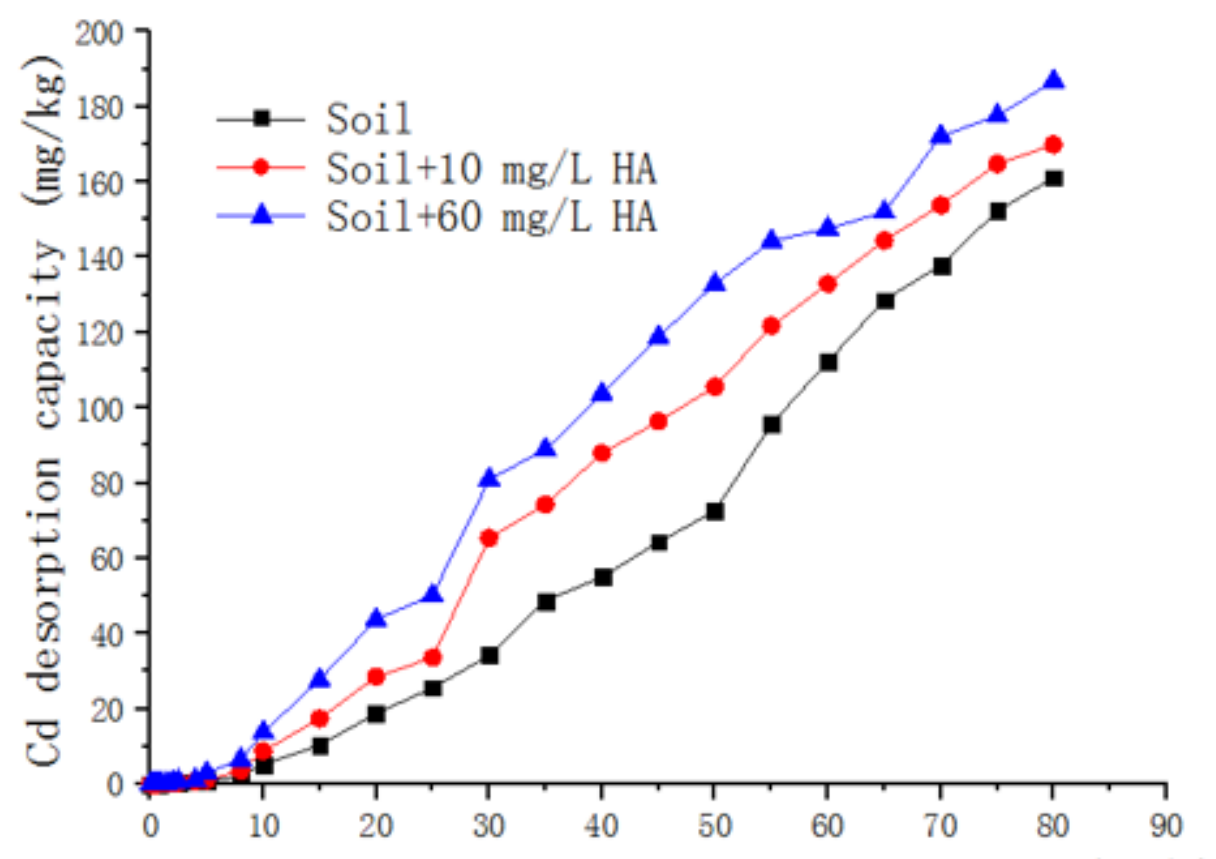

$\mathrm{Cd}$ concentration in equilibrium solution (mg/L)

\section{Figure 2}

Cd desorption capacity versus $\mathrm{Cd}$ concentration in solution in the presence and absence of HA.

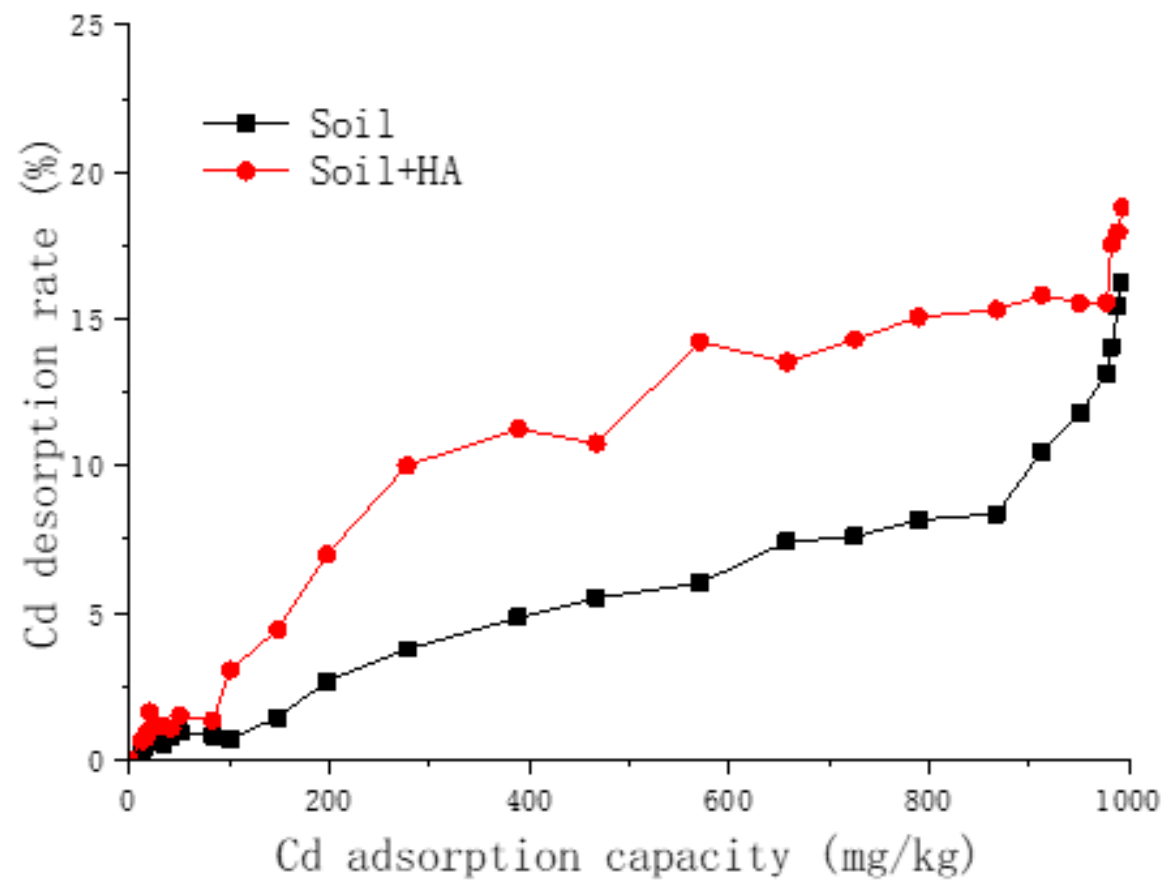

Figure 3 
Cd desorption rate versus $\mathrm{Cd}$ adsorption capacity for reclaimed soil in the presence and absence of $\mathrm{HA}$.

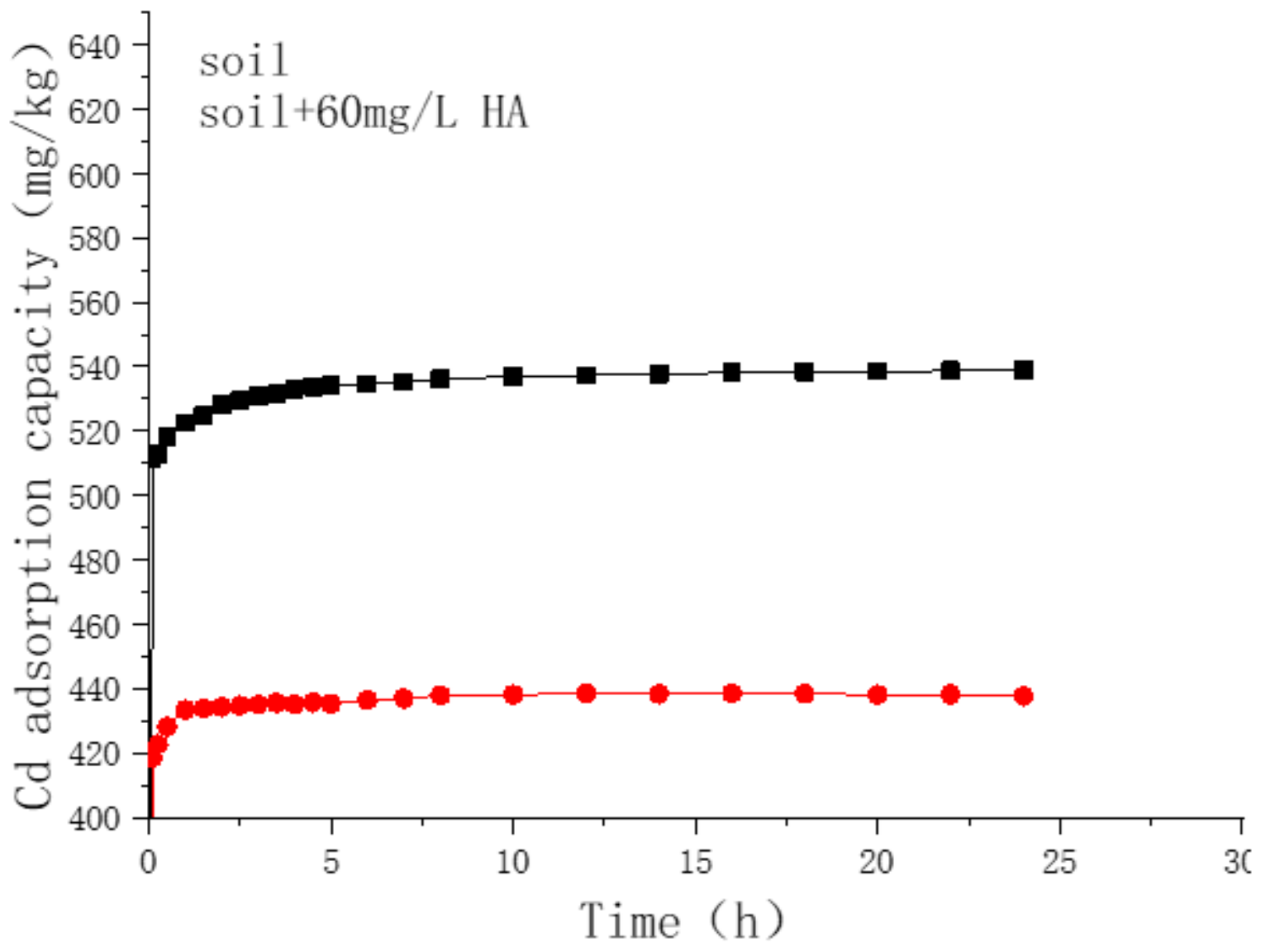

Figure 4

Kinetic curves of Cd adsorption in reclaimed soil in the absence and presence of HA. 


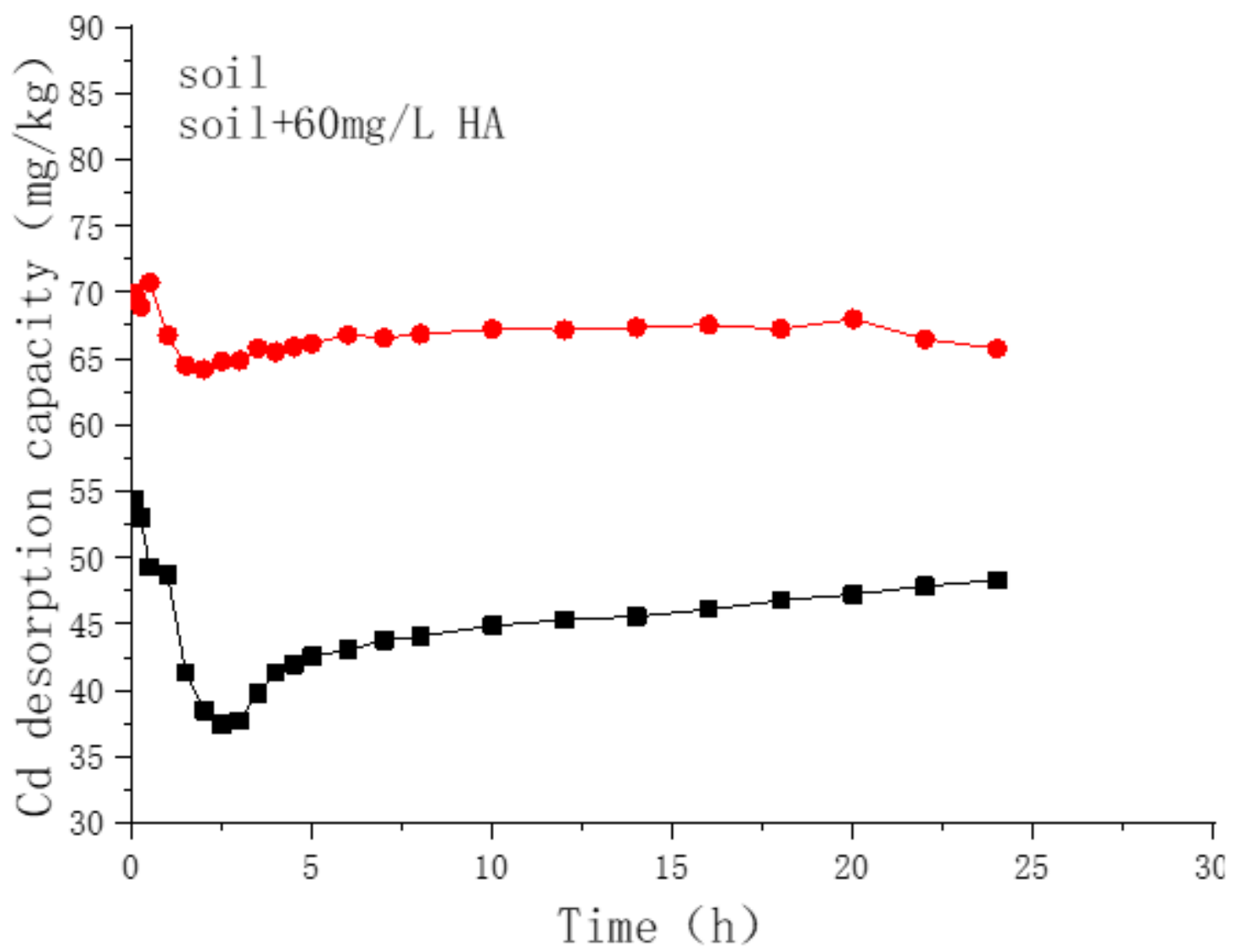

Figure 5

Kinetic curves of Cd desorption from reclaimed soil in the presence and absence of HA. 


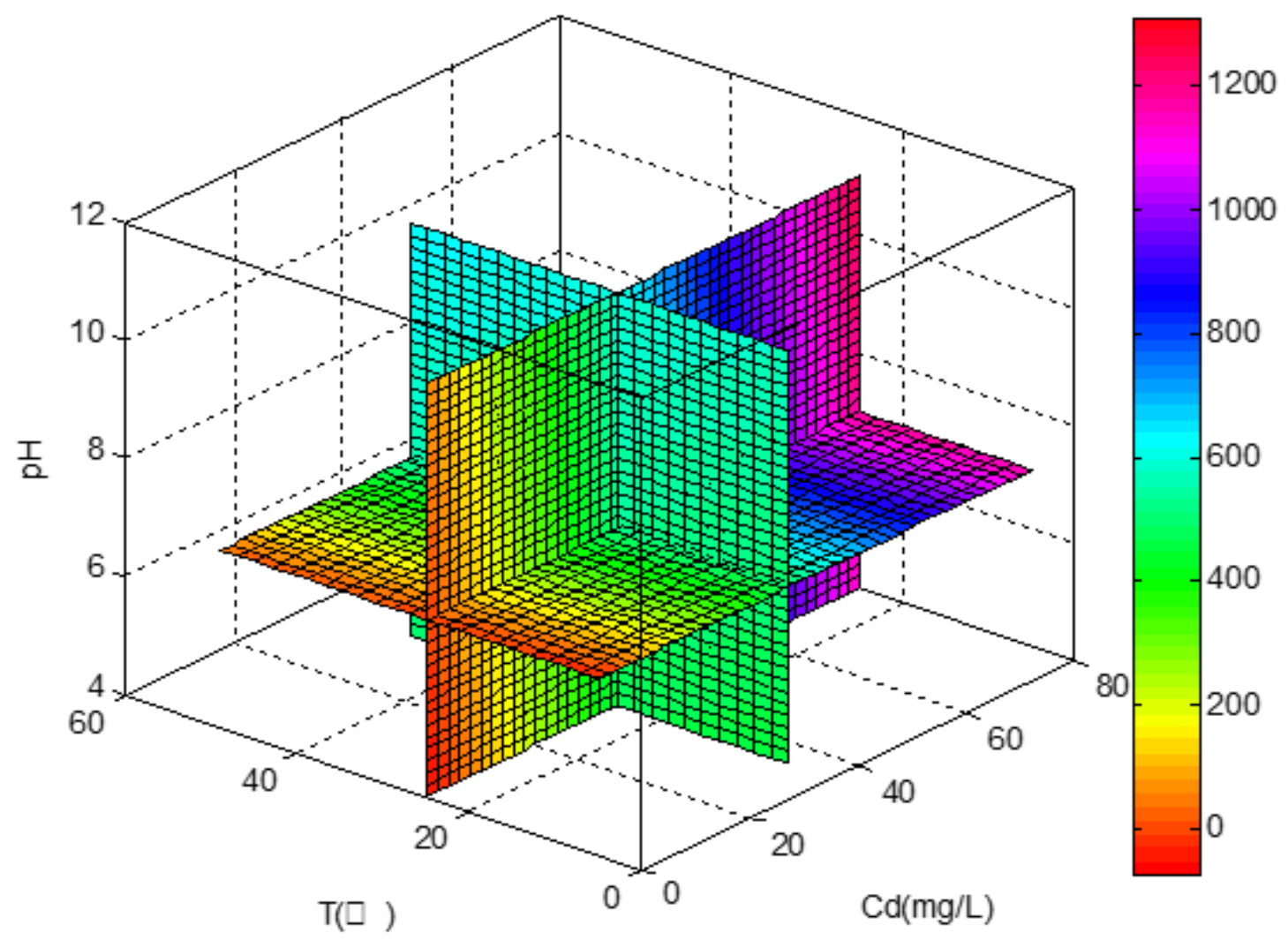

Figure 6

The coupling of $\mathrm{T}, \mathrm{pH}$, and $\mathrm{Cd}$ at $\mathrm{HA}=60 \mathrm{mg} / \mathrm{L}$. 


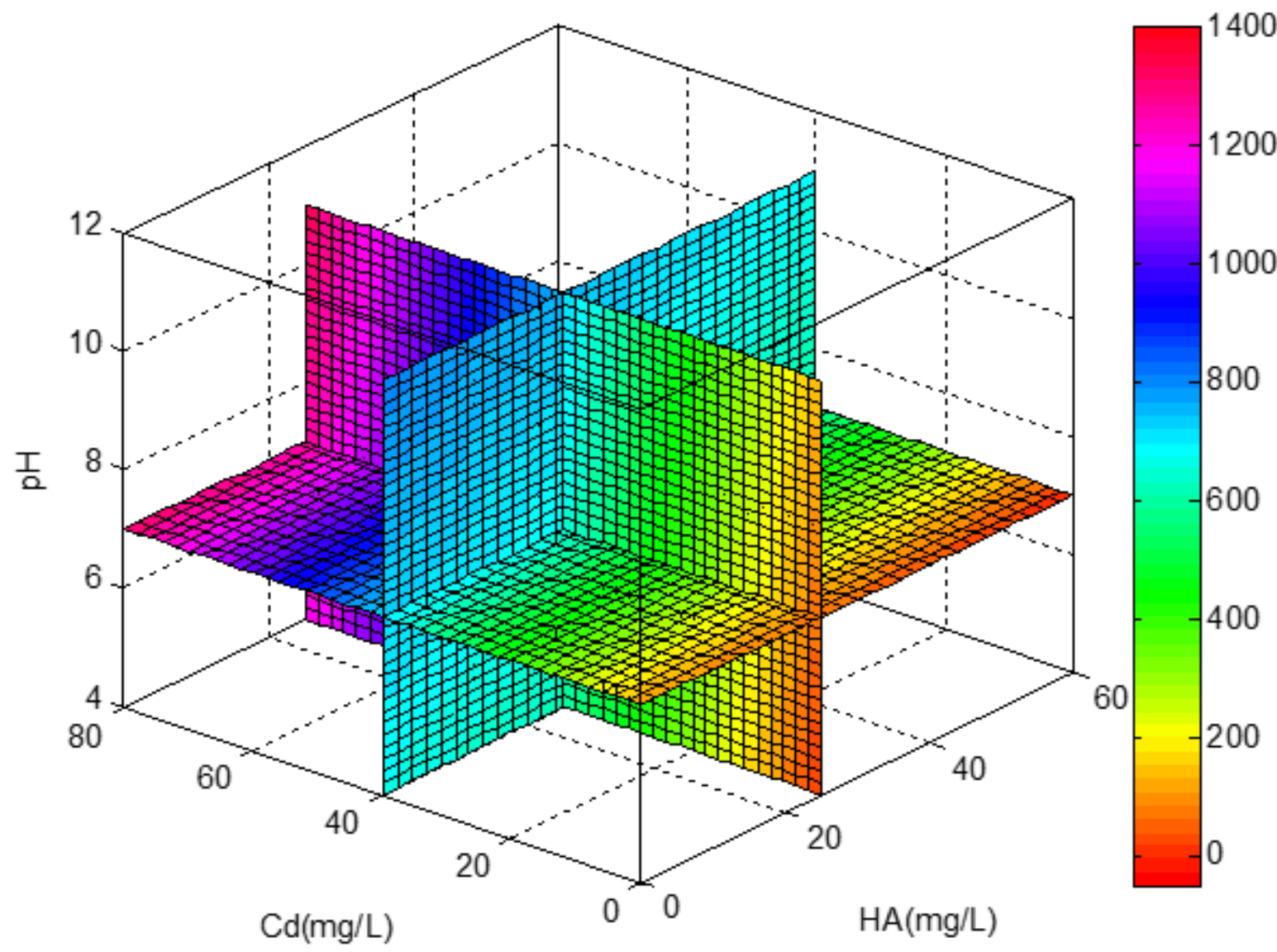

Figure 7

The coupling of $\mathrm{HA}, \mathrm{pH}$, and $\mathrm{Cd}$ at $\mathrm{T}=25^{\circ} \mathrm{C}$. 


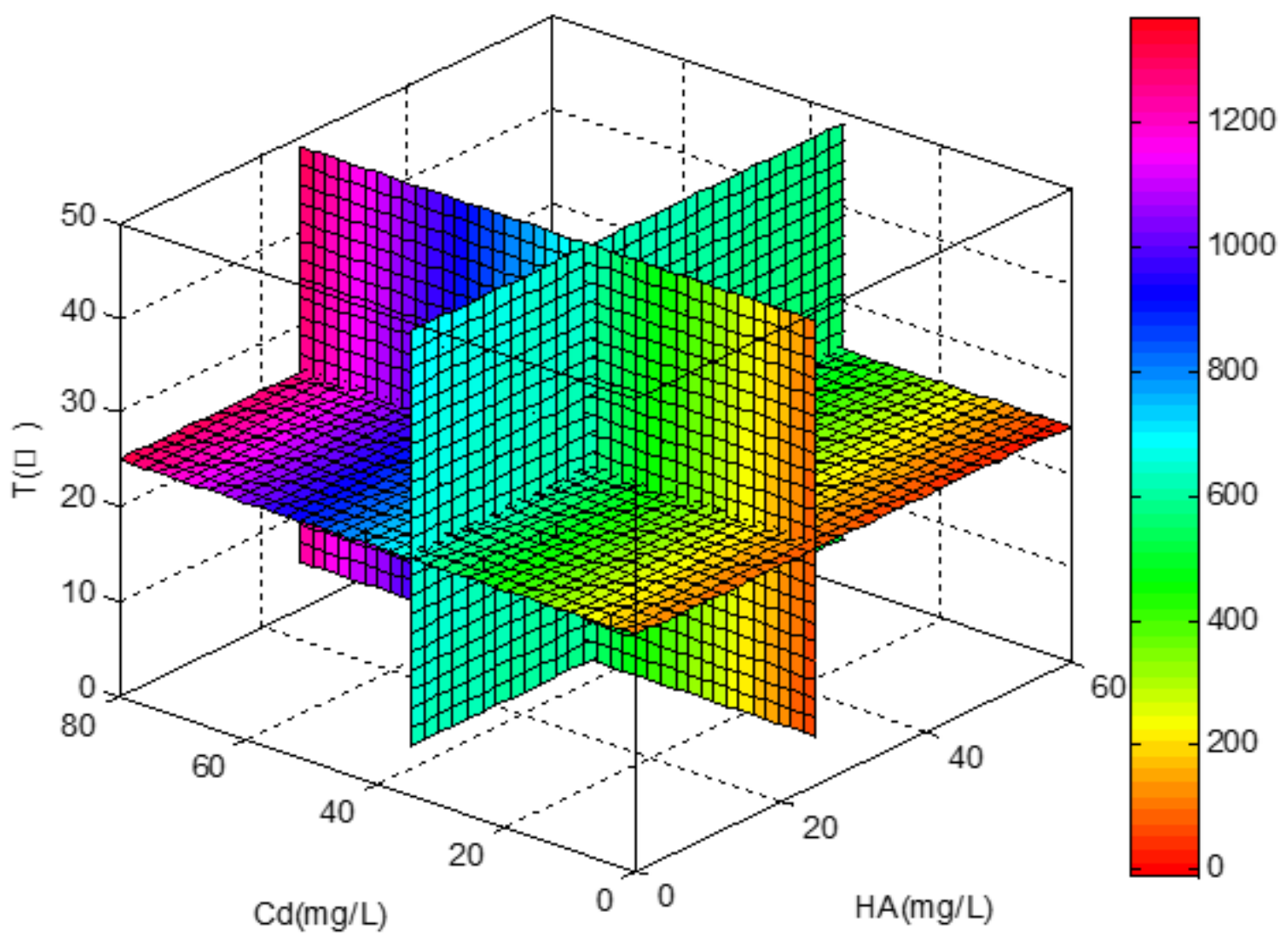

Figure 8

The coupling of $\mathrm{HA}, \mathrm{Cd}$, and $\mathrm{T}$ at $\mathrm{pH}=7.5$. 


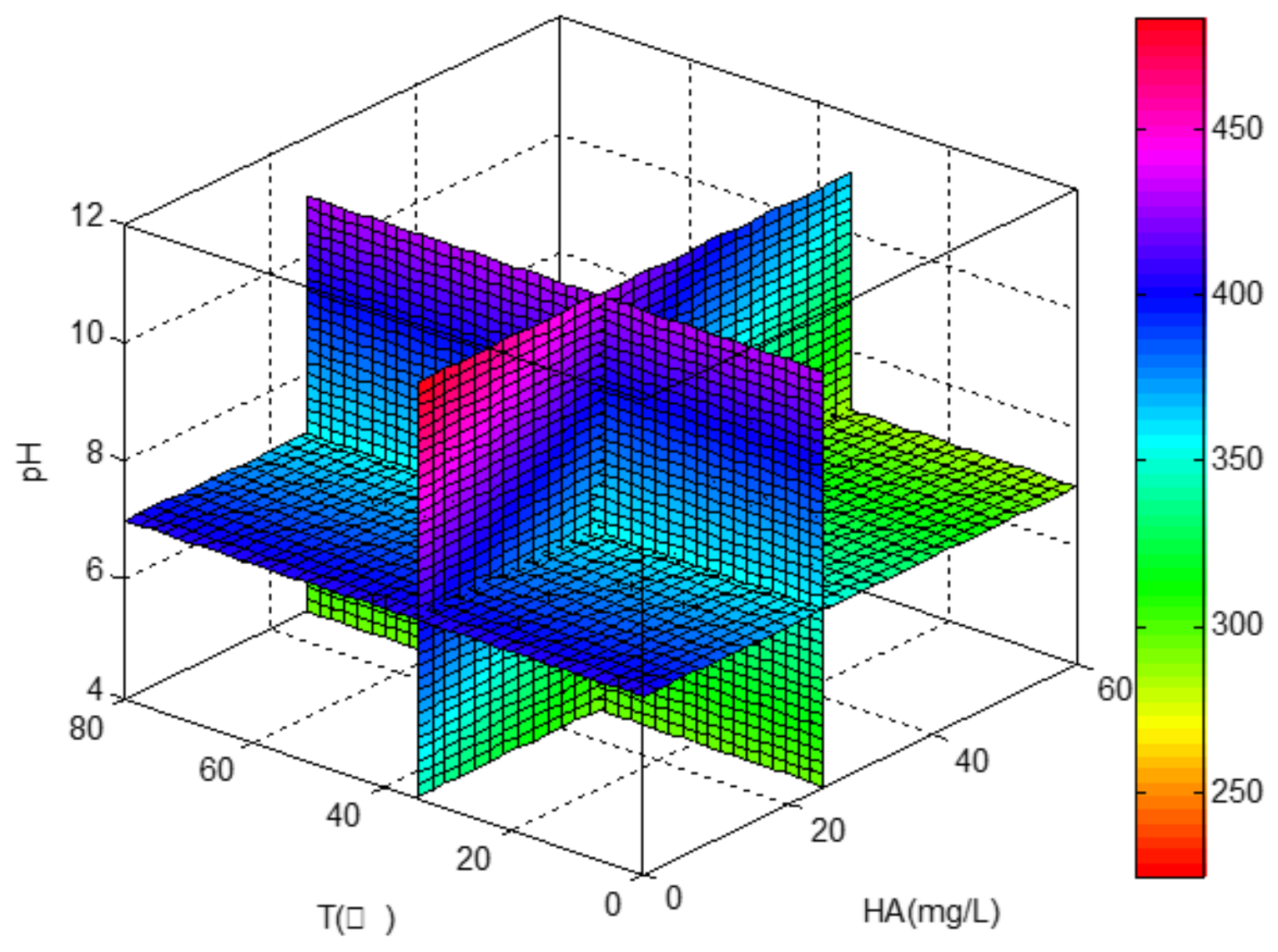

Figure 9

The coupling of $\mathrm{HA}, \mathrm{T}$, and $\mathrm{pH}$ at $\mathrm{Cd}=20 \mathrm{mg} / \mathrm{L}$. 


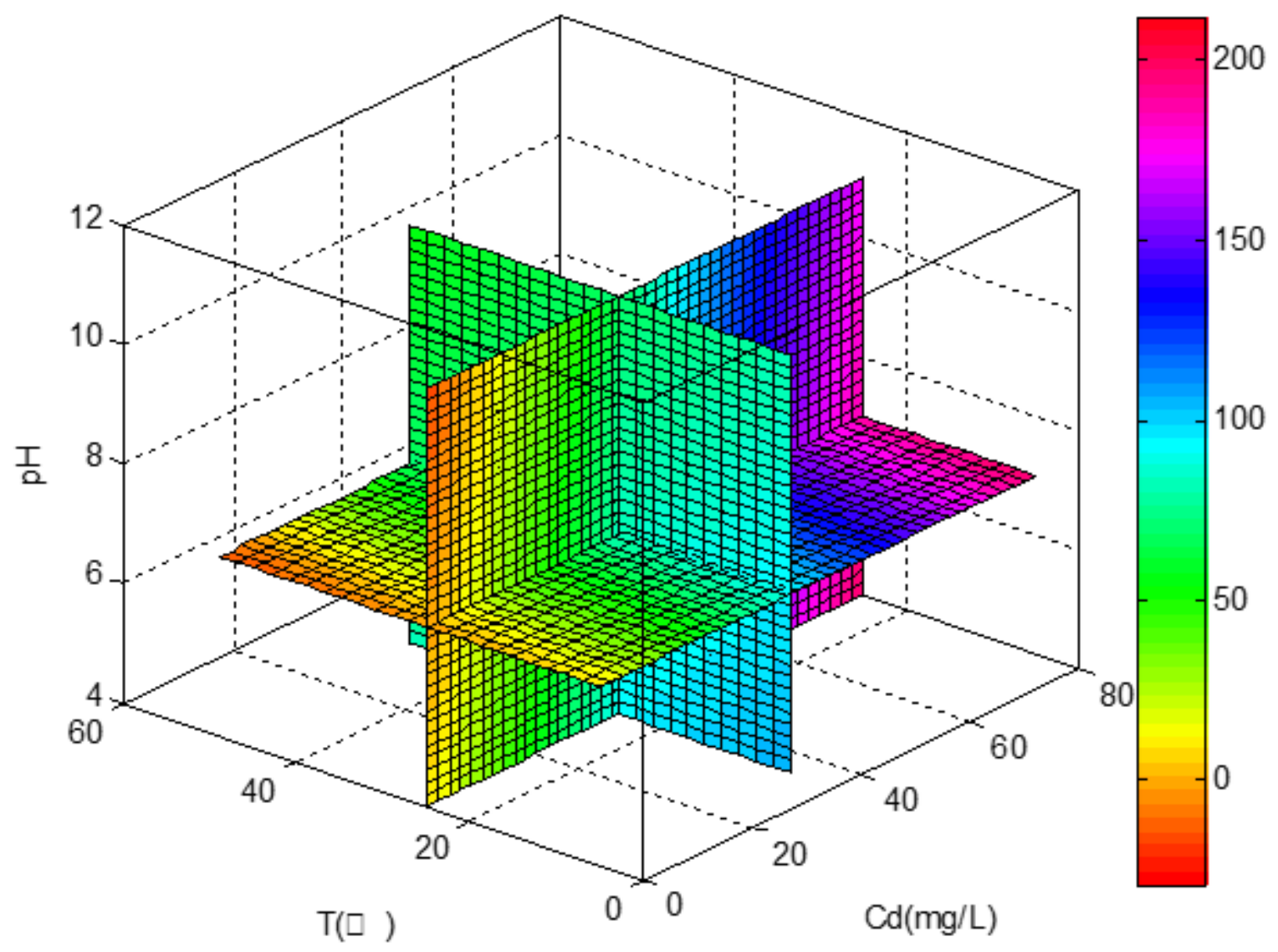

Figure 10

The coupling of $\mathrm{T}, \mathrm{pH}$, and $\mathrm{Cd}$ at $\mathrm{HA}=60 \mathrm{mg} / \mathrm{L}$. 


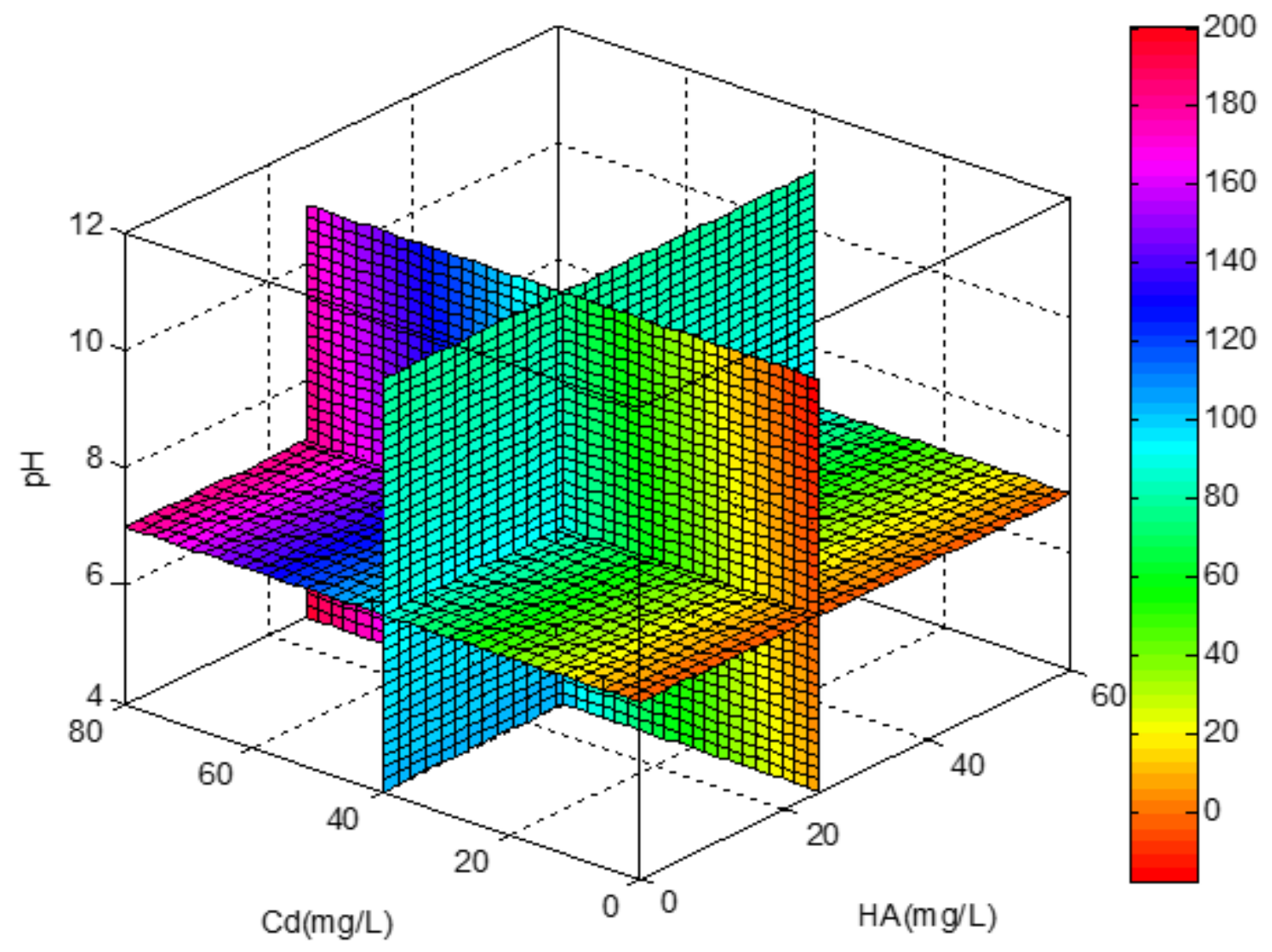

Figure 11

The coupling of $\mathrm{HA}, \mathrm{pH}$, and $\mathrm{Cd}$ at $\mathrm{T}=25^{\circ} \mathrm{C}$. 


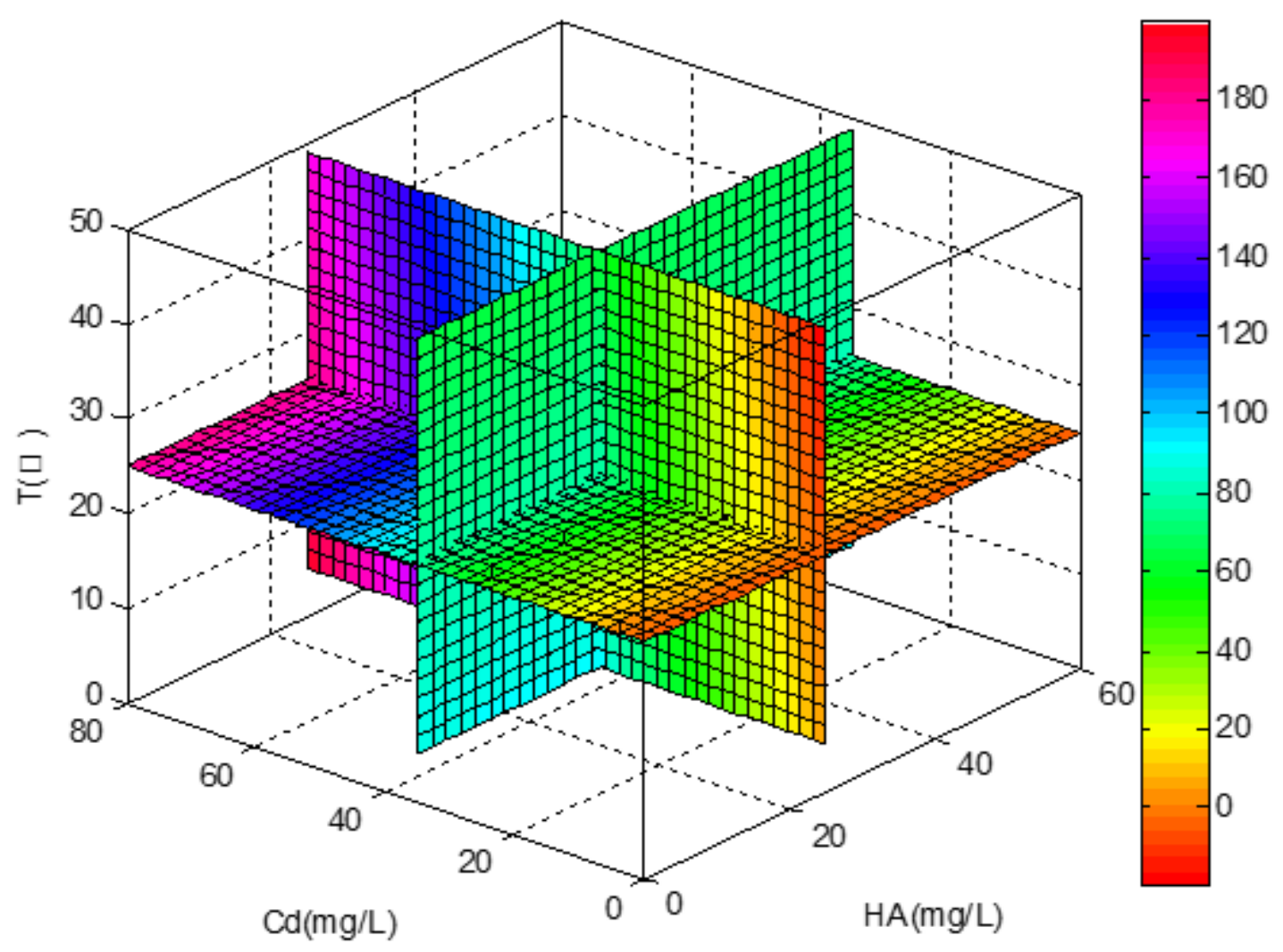

Figure 12

The coupling of $\mathrm{HA}, \mathrm{Cd}$, and $\mathrm{T}$ at $\mathrm{pH}=7.5$. 


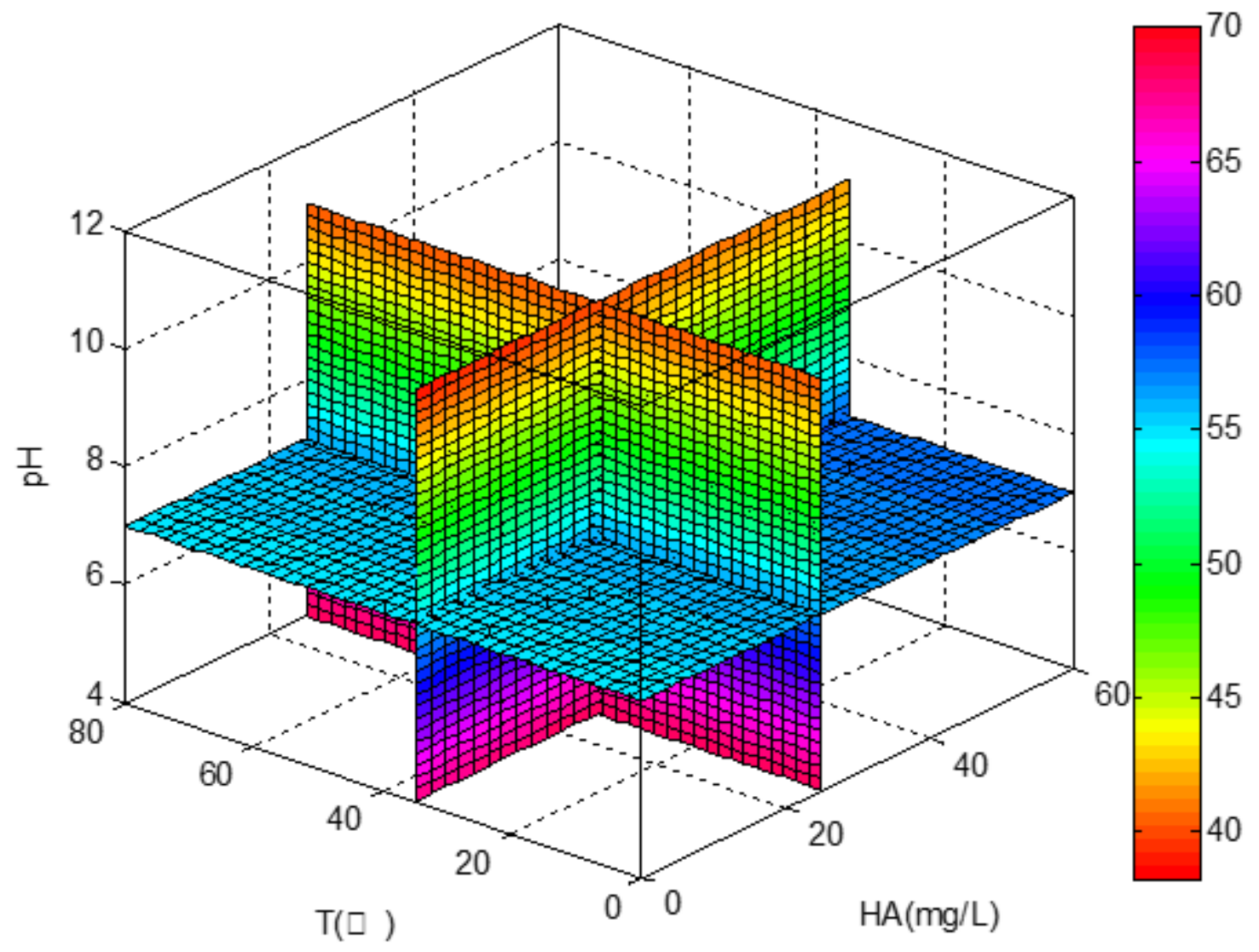

Figure 13

The coupling of $\mathrm{HA}, \mathrm{T}$, and $\mathrm{pH}$ at $\mathrm{Cd}=20 \mathrm{mg} / \mathrm{L}$. 